\title{
Th. Sect.
}

THE ULTIMATE PROGNOSIS

in cases of

ECIAMPSIA and ALBUIINURIA

of

PREGNANCY.

23.0 .1928$.

Jessie C. B. Sym, M.B.,Ch.B. 


\section{THE UITIMATE PROGNOSIS in CASES of ECLAYPSIA.}

\section{and ALBUIINURIA of PREGNANCY.}

Eclampia has been recognised for many years as one of the most formidable risks which the childbearing woman has to face. Stroganoff states (Journ. of Obst. and Gyn. Brit. Emp. $1923 \times x \times x$ p.1.) that out of every 10,000 labours four women die of Eclampsia and that 5600 women die annually of Eclampsia in Europe alone. From the Registrar's Reports for England and Wales, Scotland and Ireland it appears that on an average 600 women die annually in these islands of Eclampia. Further, since $70 \%$ of these women are pregnant for the first time, 400 women die with their first child, the majority, had they lived, would probably have had other children. The foetal mortality is, and, since the disease frequently appears while the child is still premature, must remain, extremely high. Williams ( Obstetrics. 5th Edition.p.622) estimates it at $50 \%$, but considers that not more than a third of the children leave Hospital alive as owing to prematurity the neo-natal death rate is also high. At the Royal Maternity Hospital, Edinburgh, $44 \%$ of the children of eclamptic mothers left the Hospital alive. Therefore since it attacks mainly the young child bearing woman and the foetus drawing to maturity, Eclampsia, although relatively a rare disease, is of importance to every race in which it occurs: 
If further, the surviving mothers are incapacitatedeither partially or totally for further child-bearing, the increased gravity of the disease is at once apparent.

As regards Albuminuria of Pregnancy the position is rather different. Eclampia is always severe; the severity of Albuminuria varies from a mild Albuninuria in the later weeks of pregnancy to 'pre-eclanpsia." The prognosis for the lother under efficient treatment is fairly good but for the foetus, owing to the frequency of premature labour and still birth, it remains poor. Albuminuria during pregnancy is, however, an extremely common condition. It occurs, excluaing the physiological Albuminuria of labour, in 3.5\% of all pregnant women. (Eden and Holland Manual of Midwifery 6th Edit. $p 96$ et seq.) If it affects the health of so large a percentage of child-bearing women, it is a serious disease especially if the illeffects should persist after the pregnancy. If it impaired the ability of these women for the bearing of future healthy, full-time children, it is from the point of view of the race and not of the individual in some respects an even more serious disease than Eclampsia.

An attempt has therefore been made to find out whether a woman who has suffered from one of the later toxaemias of pregnancy is damaged either in regard to to her subsequent health or her child-bearing capacity and with this object in view the following investigation has been carried out. 


\section{ECIAMPSIA.}

Between the years 1st Harch 1921 and 1 st Harch 1926, 158 cases of Eclampsia were treated at the Royal Maternity and Simpson Memorial Hospital, Edinburgh, and of these 28 died in Hospital. An endeavour was made to trace the 130 survivors; this was successful in 50 instances. In addition 24 patients who had had Eclampsia in the same Hospital between the jears 1919 and 1920 were also interviewed and examined. Thus a record has been made of 74 women who survived an attack of Eclampsia which occurred not more than 9 years ago and not less than 3 years ago.

A diagnosis of Eclampsia was made on all these patients on their admission to the Hospital and was unchanged when they were discharged. Cases of "Nephritic Toxaemia", "Uraemia" etc. have not been included in the series. All the cases will comply with the following definition of Eclampsia:- "A disease occurring in the pregnant, parturient or puerperal woman, showing the signs and symptoms of acute Toxaemia, including convalsions, for which medical causes, such as Epilepsy, can be excluded."

Age. The average age of the patients when they had Eclampsia was 26.93 jears. The youngest patient was 17 ; the eldest was 47. Four patients were less than $20 ; 10$ were 40 or more; 36 were between 20 and $29 ; 24$ were between 30 and 39.

43 of the 74 women were primiparae when first 
attacked by Eclampsia. The average age of the primiparae was 25.89 years. Two were aged 17 ; the eldest was 42 .

9 patients were 20 or less.

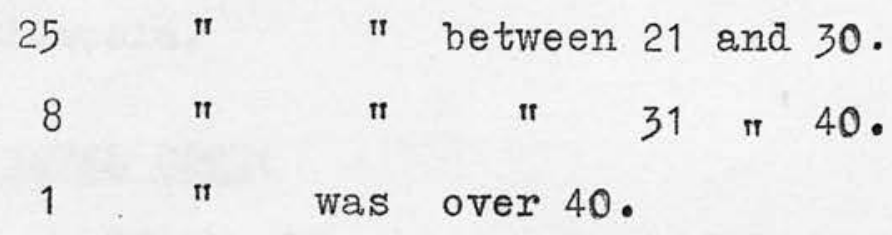

Parity. Three of the 74 patients had Eclampsia twice. At the first attack of Eclampsia the parity of the patients was as follows :-

43 patients were primiparae.

$\begin{array}{ccccc}13 & " & & 1 & \text { parae. } \\ 4 & " & " & 2 & \pi \\ 2 & \text { " } & 3 & \pi\end{array}$

1 patient was a 4 para

1 " " " 5 "

4 patients were 6 parae

$3 \pi$ "

1 patient was an 8 para

$1 \pi \pi$ \# 9 "

$1 \pi \pi$ " $10 \pi$

Thus in 58\% of this series Eclampsia occurred in primiparae.

Of the 3 patients who had Eclampia twice the first attack occurred. in 2 cases in women pregnant for the first time, and in the third in a woman pregnant for the second time, the first pregnancy having been apparently normal. The second attack of Eclampsia 
occurred in the immediately succeeding pregnancy in two cases; in the third case there were two apparently normal pregnancies resulting in full-time living babies which intervened between the two pregnancies complicated by Eclampia.

\section{ANTE-NATAI CARE.}

Of the 77 pregnancies which terminated in Eclampsia only 14 were under medical supervision. In many cases this was of a very perfunctory and inadequate sort but not in all. Three patients developed Eclampsia while in Hospital under treatment for severe Albuminuria. On the other hand it is reasonable to suppose that only a small number of the 63 women who had no medical care whatever in pregnancy would have developed Eclampsia had they been under medical supervision. This supposition is strengthened by the fact that the majority of patients had prodromal symptoms of some kind or other, and also by the observations of others - e.g. J.S. Laurence (Amer. Journ. Obst. and Gyn. Harch 1925) compares two parallel series of pregnancies. One series were given antenatal supervision and the other not. Eclampsia occurred in both series but was almost six times more common among the unsupervised (1708) cases. J.P. Greenhill also corroborates these results (Journ. Amer. Med. Assoc. July 24 1926. p. 228) for he found that of the cases of Eclampsia which we was investigating $18 \%$ had good ante-natal care, 59\% no ante-natal care, and the remainder some ante-natal 


\section{PREDROMAI STIPTOMS.}

Eight patients state that they had no warning symptoms but became without warning unconscious, although on questioning most admit that they had at least headache for a short time before. One woman, however, became unconscious in her sleep. The remainder were doing their usual work until they became suddenly ill and neither they nor their friends had noted anything amiss. Two of these patients were under medical care. One, who developed post-partum Eclampsia was seen by a doctor two days before she went into labour; nothing abnormal was noted; her urine was tested. The other, who had severe antepartum Eclampsia, was seen by her doctor one week before the fits started and nothing abnormal was noted It appears therefore that until our knowledge increases some patients will develop Eclampsia even under efficient care.

The remaining patients (70) all noticed oedema, and all those who had their urine tested are known to have had Albuminuria. It is uncertain whether the Alb uminuria or the oedema appears first, or whether they appear together, as in the majority of cases it is the oedem which leads the patient to seek advice. In only one case was the oederna not the first symptorn to be noted; in this case headache was what was first noticed.

Headache was the next most common symptom and was noted by 43 patients. Four patients had headaches for 
6 to 10 weeks before the onset of fits; the remainder had severe headoche for a much shorter time - on an average 6.2 days. Agonising headache preceded the fits for an hour or two in most cases.

Twenty patients complained of eye symptoms which in six cases amounted to blindness. The average duration of this symptom was three days. The headache is intimately associated with the eye symptoms; all patients who noted the latter complained of the former.

Eight patients complained of epigastric pain, coming on in attacks and lasting for a few hours. They were in all cases associated with headache.

The average interval between the onset of symptoms and the development of Eclampsia was 4.8 weeks, and it varied from 14 weeks to no time at all.

\section{IENGTH OF GESTATION.}

44 patients had reached full time. The average gestation lay between 37 and 38 weeks and the shortest was 22 weeks. This gestation occurred in one of the primiparous patients and labour came on spontaneously. CONVULSIONS.

Convalsions occurred in all cases. The average number was 5. The greatest number from which any patient suffered was $16 ; 2$ patients had only one fit.

In 25 cases the fits were ante-partum, in 15 intra partum, and in 13 ante and intra partum, in 5 intra and post partum and in 1 ante and post partum. In 3 cases the type of convulsion has not been noted. 


\section{FOETAT HORTAIITY.}

$38-96 \%$ of the labours resulted in still births or macerated foetus. The average length of gestation in 30 labours of which a still birth was the result was 35 weelrs; 11 labours were at term.

TWIN PREGNANCIES occurred 7 times in this series. This incidence is unusually high even among cases of Eclampsia where the incidence is usually $4.7 \%$ (T.Watts Eden. Eclampsia. Journ. of Obst. and Gyn. Brit. Emp. 1922 p. 386.) According to Veit's analysis of 20 million labours the usual incidence of twins is $1.17 \%$.

\section{ALBUITINURIA.}

All patients had on admission a large amount of albumen noted by. a double or treble plus. Casts were noted in the majority of cases.

\section{BIOOD PRESSURE.}

Blood pressure readings have been made in all the cases analysed. If of these the highest reading is taken, the average highest systolic pressure is $176 \mathrm{mr}$.HG and the average highest diastolic $117 \mathrm{~mm} \cdot \mathrm{HG}$. The highest systolic pressure noted was $240 / 180 \mathrm{~mm} \cdot \mathrm{HG}$; this same figure also gave the highest diastolic reading $-180 \mathrm{~mm}$.HG In noting the maximum blood pressure it was seen that the systolic readings showed a much wider variation than the diastolic.

\section{TREATMENT.}

1. OBSTETRICAT. Induction of labour was performed 7 
times, twice by means of a de Ribes bag, 5 times with Quinine and Pituitrin.

Caesarian section was done three times. Forceps were applied in 24 cases; extraction of breach was done twice. The remainder of the patients had spontaneous deliveries.

11. MEDICAI. Medical treatment consisted of gastric and colonic lavage with the administration of Hagnesium Sulphate and Calomel. Morphia was given hypodermical and venesection done if required. Veratrone was given to 14 of the patients; Scopolamine and Hyoscin to 5 .

After delivery the patients were kept on a carbohydrate diet to which later fish was added. A certain number were given Thyroid. Any complications in the puerperium were given appropriate treatment.

\section{PUERPERIUIS.}

If one woman who stayed two months in Hospital after labour on accountof Pyelitis is excluded, the avera.ge stay in Hospital post partum was 17 days.

A number of patients had some bacterial infection post partum but in no case did this become serious. The different forms which this took are as follows :-

Pyelitis 4 cases.

Pyurea

3 "I

Phlegmasia Alba Dolens 2 cases.

Cellulitis $\quad 1$ case

Hild uterine sepsis 2 cases. 
Furunculosis 1 case.

Pleurisy

$1 \pi$

The remainder $81.8 \%$ of the puerperia were uneventeul.

on

Urine/discharge. No consistent record of this has been kept prior to 1923. Of the 50 cases which occurred in the following years 26 showed albumen on discharge but in three of these cases it was thought to be due to pus alone; 22 cases were albumen-free, and in 3 cases the state of the urine was not noted.

Blood pressure readings on discharge have not been taken before 1924 and not invariably since then. In some cases both urine and blood pressure are normal; in some cases neither, and in other one is abnormal although the other is normal. No inference can be drawn safely from so few figures, especially as the observations are not made at the same distance of time from the delivery.

RECORD of Length of Stay in Hospital with Blood Pressure and Presence or Absence of Urine on Discharge.

Time spent in

Hosp.Post Partum. Days.

11

11

21

11

15

18

19

13

10

25

19

25

12

13
Albumen in

Urine on disch.
B.P. on disch. Iín. HG.
$130 / 90$. $164 / 110$. $130 / 85$. $150 / 110$. $160 / 110$. $112 / 90$. $140 / 110$. $185 / 100$ $134 / 100$ $124 / 70$ $104 / 60$ $108 / 76$ $160 / 130$. $170 / 125$. $140 / 80$. 
From the data given it may be seen that this series is typical of the type of Eclampsia dealt with at the Maternity Hospital, Edinburgh, except that the fatal cases do not, of course, appear. Before attempting to assess, however, the permanent damage, if any, that Eclampsia has caused to these women, the state of their health prior to Eclampsia must be investigated, as defects noted subsequently may have been present previously. The information from Hospital records has been supplemented by questioning each patient personally as to her health before Eclampia. Her doctor has been written to for corroboration of her statements where this seemed advismade

able. A record has been as complete as possible of all functional or organic defects and also a record of the infections from which these patients suffered. In the case of the multiparae evidence as to how she stood the test of previous pregnancies has been collected. Enquiry has also been made as to whether they had any illness, however trivial, during the pregnancy which terminated in Eclampsia.

J.E. Lawrence in a paper on the Relation of Extraneous Disease and Subsequent Organic Defect to Eclampsia (Amer. Journ. Obst. and Gyn. Harch 1925) considers that general infections such as Influenza, Pneumonia, Rheumatic Fever, Scarlet Fever and Furunculosis render a woman more liable to Eclampsia, and that the organic defects most closely connected with it are Punctional defects of the renal, intestinal and cardiac apparatus. 
J.E.Talbot with many others considers that focal infection plays an important part in the etiology of Eclampsia, (Toxaemias of Pregnancy - Chronic Sepsis a.s an Etiological Factor. Amer. Journ. of Obst. and Gyn. Dec. 1923) as he considers that the placental infarct is the result of a haematogenous infection and that repeated emboli of Bacteria so strain the metabolic balance that ultimately toxaemia of some degree or another occurs., The difficulty of proving this theory is obvious, as probably few people exist, at any rate of 'Hospital class', in whom some septic focus cannot be found.

The present series consists of 74 patients. Disregarding the reproductive ability of the multiparae, 33 of the 74 patients give no history and show no traces of antecedent disease, of these 16 were primiparae and 17 multiparae. According to their own account these patients were exceptionally robust women.

20 patients have suffered from exanthemata, excluding Scarlet Fever and Diphtheria of which more particular information is given later. 2 patients suffered Prom Tuberculosis and 3 from Pleurisy probably of tuberculous origin, but when they acquired Eclampsia. these lesions were apparently healed and since then they have remained quiescent.

3 patients had had Rheumatic Fever; in one a. wellcompensated valvular lesion was present. 2 other patients had cardiac murmurs which suggested a previous attack of Rheumatism and one gave a history of repeated 
sore throats.

5 natients had Diphtheria, one was a multipara. In her Eclanpsia occurred in her second pregnancy and the first pregnancy was complicated by Albuminuria. Other patients were primiparae. In all, the Diphtheria occurred in childhood or adolescence and so far as is known was not complicated by Nephritis.

9 patients have had Scarlet Fever; 5 were primiparae when they had Eclampsia. The Scarlet Fever was uncomplicated so far as is known. The following notes are of some interest in the case of the multiparae :Mrs. M. had Scarlet Fever when she was 27. Her first child was born when she was 29. In this and the subsequent pregnancy she probably suffered from mild Albuminuria. (Proof is lacking as she did not consult a doctor.) Eclampia occurred in the third pregnancy. She was well between pregnancies. She is a thin, anaemic woman now. Her renal efficiency tests are satisfactory. Irs. H. had Scarlet Fever with Hephritis when she was 5. She had Eclampia in her seventh pregnancy. The first and sixth pregnancies were normal, the others were probably, but not certainly, accompanied by mild Albuminuria.

Mrs. S. had Scarlet Fever in childhood. Her first pregnancy was complicated by Albuminuria; her second ended in Eclampsia. She is now pregnant and is very well. Her renal efficiency tests are good. Mrs. D. had Scarlet Fever twice, the second time when she was 16. Eclampsia complicated her third pregnancy, 
the two preceding being nomal. Her renal tests are unsatisfactory. She has had no subsequent pregnancies. Two other patients are worthy of special mention:Irs. B. had Eclampia when primiparous. Her only previous illness was Rheumatic Fever, but her family has a tendency to develop Nephritis. She is one of a family of 3. She and her sister had Eclampsia and her brother had chronic Nephritis. Her father, his sister and their mother also had Nephritis. Although she feels in good health now, her renal tests are unsatisfactory. She has had no more children. lirs. W. had 3 normal pregnancies, then an attack of Colitis. She again became pregnant but miscarried. Her next pregnancy (5th) ended in Eclampsia. She apparenty recovered quickly. and completely, but her subsequent reproductive history shows her impaiment. She has been pregnant 7 times since and has had Albuminuria 3 times, 3 miscarriages and 1 doubtfully normal pregnancy. She has now demonstrably impaired kidneys.

It is difficult to interpret these results fairly but I think it may be tentatively put forward that where any disease can be linked even very indefinitely with Eclampia, the Eclampsia is more likely to have occurred in a multipara. If the pregnancies antecedent to Eclampia have been normal, it is difficult to see what correlates the disease and the Eclampsia. In doing this one uses the anteceding pregnancy as the criterion of health. 
Only one patient had any disease during the preg nancy which ended in Eclampia. This was a primipara who had Influenza. It was cured two months before she had Eclam psia.

Any other diseases are noted on the table.

\section{Ilnesses occurring previous to Eclampsia.}

\begin{tabular}{|c|c|c|}
\hline No disease & 33 & patients. \\
\hline Scarlet Fever & 9 & $\pi$ \\
\hline Diphtheria & 5 & ". \\
\hline Other Exanthemata. & 22 & $\pi$ \\
\hline Tuberculosis & 2 & $"$ \\
\hline Pleurisy & 3 & $"$ \\
\hline Rheumatic Fever & 3 & $"$ \\
\hline $\begin{array}{l}\text { Heart disease ?of } \\
\text { rheumatic origin }\end{array}$ & 2 & $"$ \\
\hline Tonsillitis & 2 & $"$ \\
\hline Influenza (severe) & 2 & $"$ \\
\hline Pneumonia & 1 & $\pi$ \\
\hline Appendicitis & 1 & $\pi$ \\
\hline Alimentary diseases & 4 & $"$ \\
\hline Chlorosis & 1 & $"$ \\
\hline Cystitis & 1 & $\pi$ \\
\hline Dysmenorrhoea & 2 & " \\
\hline
\end{tabular}

\section{Previous Gestations.}

The 31 multiparous women have had 108 gestations There were 80 normal full-time pregnancies and 3 others in which the only known abnormality was that they 
terminated prematurely, 2 for no ascertainable cause and 1 as the result of an accidental haemorrhage. 11 pregnancies were complicated by Albuminuria and 1 terminated prematurely. These occurred in 7 women. 14 gestations ended in miscarriage That is to say, $23 \%$ of the multiparous patients had had Toxaemia of pregnancy at least once in a former pregnancy. This re productive disability is, however, not absolute; that is to say, normal pregnancies succed abnormal. There fore it would seem that a disability, congenital or acquired, previous to child-bearing at any rate of this degree can only predispose to Toxaemia and that some other factor must operate as well.

A record of the pregnancies previous to Eclampsia with the previous diseases is given below.

Prévious pregnancies in order of their occurrence.

3 N. $\quad 1$ Misc.

$8 \mathrm{~N}$.

$1 \mathrm{~N}$.

$1 \mathrm{~N}$.

1N .

3 N. 1 ?N, $2 \mathrm{~N}$.

$1 \mathrm{~N}$.

1 Hisc

1 Album -

$1 \mathrm{~N} .2$ ? N.

1 N. 1 ?N.

$9 \mathrm{~N}$.
Illnesses previous to Eclampsia.

Rhum. Fev.,Appendicitis. Colitis.

Measles.

Measles.

Indigestion.

Measles. 
Previous pregnancies in order of their occurrence.

3N. 1Hisc.,2N. 1Hisc.,2N.1Hisc.

2 Albea.

$4 \mathrm{~N}, 1$ Misc., $1 \mathrm{~N}$.

$1 \mathrm{~N}, 2 \mathrm{Misc}, 1 \mathrm{~N} \cdot 3 \mathrm{Hisc}$.

$1 \mathrm{NT}$.

$1 ? \mathrm{Alb} \cdot-$

$5 \mathrm{~N}$.

$2 \mathrm{~N} \cdot 3$ Albea. $1 \mathrm{~N}$.

1 Alb ${ }^{e a} \cdot$

$7 \mathrm{~N}$.

$1 ?$ Alb. $\stackrel{\text { ea }}{ }$

$1 \mathrm{~N}$.

2 Misc.

$7 \mathrm{~N}$.

$6 \mathrm{~N}$.

$2 \mathrm{~N}$.

$1 \mathrm{~N}$.

108 Gestations.

83 Normal.

14 ended in Miscarriage.

11 were complicated by Albuminuria.

Foetal Hortality in Previous Pregnancies.

As a result of the 94 labours, 92 living children were born and there were 3 still births. Twins occur-
Illnesses previous to

Eclampsia.

Scarlet Feverftwice.

Pleurisy, Measles, Whooping cough, Dyspepsia.

Wh. Cgh. Jaundice.

Scarlet Fev. with Neph. and other Exanthemata.

Measles, Wh. Cgh. Dyspepsia.

Scar. Fev.,Diphth.

Rheum. Fever.

Scar. F. twice. 
occurred once in the series. One still birth occurred where the labour was premature; one in a patient with Albuminuria and one ss a result of ante-partum haemorrhage.

\section{Recovery from previous Pregnancies.}

All patients recovered rapidly and completely.

This finishes the record made of these patients up till the time of their having Eclampsia. Since then some have born children; some have been in poor, good or indifferent health and some have died. The surviviry women have been personally questioned about their health Their doctors have also in some cases given information regarding their health and their subsequent pregnancies and information regarding this has also been obtained from Hospital records. In some cases little certain information could be obtained regarding subsequent pregnancies, as patients merely had a mid-wife to attend them at their confinement. When the history given indicates that some abnormality was present, but proof of this is lacking, the abnormality is noted preceded by a question mark. E. G. A patient who states that she suffered from swelling of the feet and legs in the last 3 weeks of pregnancy and that she had headaches for the last 2 weeks; this pregnancy is noted as'? Albuminuria.' In adition each patient has been examined at the present time at the Katernity Hospital with the exception of one or two country patients whose own doctors sent a report of their present health, as they were unable to attend. A record has been made of these find- 
findings. The condition of the heart and arteries wo specially noted; the blood pressure was taken by the Baumanometer using the Auscultatory liethod. The urine was examined. If albumen was present, a centrifuged

- catheter specimen was microscopically examined.

Patients were further asked to allow a speciment of their blood to be taken for estimation of the urea and non-protein Nitrogen. The great majority consented and also allowed a Urea Concentration Test to be done on themselves. The blood specimens were taken on the patients' arrival i.e. $10 \mathrm{a} \cdot \mathrm{m}$. and as most had had breakfast the blood was not 'starving'. The Urea and Non-protein Nitrogen estimations were done in the Biochemical Iaboratory of the Royal Infirmary, Edinburgh. The lificro Kjeldahl method was used in estimating the Non Protein Nitrogen and the Urease method in estimating the Urea Nitrogen.

The Urea Concentration Tests (Haclean's) were done by myself. First, second and third hour specimens were obtained. The Urea did not produce diuresis in any of these patients; all specimens were under $20 \mathrm{cc}$. Haciean's method was followed exactly and a Urea concentration of 2 or more was considered satisfactory. This test gives very little trouble, is one to which patients willingly submit when they understand what is required, and is extremely valuable in this type of work.

\section{DEATHS.}

Of the 74 patients 3 have died since they have 
had Eclampsia. (4\%).

1. Of a second attack of Eclampsia.

This patient had Eclampsia for the first time when aged 18. She had prodromal symptoms for two weeks. Labour came on spontaneously at the 32nd week; the child died of prematurity. She had 9 ante partum fits. When she was discharged from the Hospital, she had still Albuminuria, but according to her parents was in good health. She became pregnant two jears later and developed fulminating Eclampsia at term. There were no prodromal symptoms. She died shortly after the delivery of a live child. She never had ante natal care.

11. This patient developed Eclampsia with her first pregnancy when aged 32. She had no ante-natal care. Symptoms dated from the 18th week. She had one fit at the 24 th week. She aborted at the 26th. week. During the intervening fortnight the blood pressure was very high and albumen $\mathrm{xxx}$ in the urine. She became pregnant again two years later, having been in good health in the interval, and died on the 17th day of the puerperium of pulmonary embolism. The pregnancy and labour were according to the history uncomplicated. 111. This patient developed Eclampsia at term when pregnant for the first time. She had no ante-natal care. On admission no foetal heart was heard and the pelvis was found to be so contracted that a craniotomy was necessary. Patient left hospital 'well' but died shortly after.. I have been unable to find out 
the cause.

RECOVERIES.

The 71 patients who are still alive were asked to state whether they felt completely recovered from their illness, and how long it was before recovery took place, if ever, and what they felt wrong until it did. Excluding the two patients who had Eclampsia twice, the replies are as follows :-

53 recovered completely and rapidly, i.e. in less than three months.

13 recovered completely but slowly.

3 recovered only partially. Two of these patients state that they are not so mentally alert as they used to be, and all three say that their capacity for work has decreased. One patient who had Eclampsia twice belongs to this group; her first recovery was rapid and complete. The other patient who had Eclampsia twice recovered rapidly and completely both times. 6 patients state that for a period of $1-6$ months in the puerperium they had severe headaches, similar in type to the headaches which preceded the fits.

\section{Treatment after discharge from Hospital.}

10 patients were put on Protein restricted diets by their doctors for varying periods. 4 were treated with Thyroid. .

\section{Ilnesses subsequent to Eclampsia.}

Very few patients have had any illness for which they had medical advice. The following is 
the list of ailments :-

Goitre

1 patient.

Appendicitis

II

Tonsillitis

Whooping Cough

Diphtheria

GENERAI HEALTH subsequent to Eclampsia.

Patients were as ed to state generally and

vaguely in what health they had been since Eclampsia excluding in their replies any reference to subsequent pregnancies. 48 state that their health is as good as it was; 14 have only fair health and 9 have poor health. This 'poor health' is not of a type for which women go to a doctor. They have "no energy, not the same life as before", but no definite complaint and usually ascribe the feeling to the strain of childbearing. It may be said that these enquiries are of too vague a nature to be of any value but this is not so in the view of the writer. There is nothing more suggestive than this complaint from a woman who is pale, sallow, slightly anaemic, thin, with darkshadowed eyes. Further investigations will usually reveal that her renal efficiency tests, or her reproductive history or both are unsatisfactory.

\section{Defects noted as the result of clinical examination}

of 71 patients.

In 39 patients no defect was found; they all felt in the best of health. The defects noted in the 
remainder are given below ex cept for any faultsin the renal or cardio-vascular systems which are noted more particularly later.

$\begin{array}{lc}\text { Anaemia } & 12 \\ \text { Ch. Constipation } & 6 . \\ \text { Advanced Pyorrhoea } & 7 \\ \text { Bronchitis } & 1 \\ \text { Enlarged Thyroid } & 2 \\ \text { Iryxoedema. } & 1\end{array}$

Enlarged tonsils (chronically inflamed) 3

Henorrhagia 1

Dyspepsia 1

Neurasthenia 1

Hemiplegia (result of cerebral haemorrhage) 1. All these patients are of hospital class and therefore the number who have anaiemia - of a mild degree - is high. Nearly all, also, had some oral sepsis and the 7 noted cases of Pyorrhoea were all severe.

Result of examination of renal and cardio-vascular systems. In 54 of the 71 patients the tests mentioned above were satisfactory, i.e. $76 \%$. 12 of the patients gave at least one result which was below par - $16.9 \%$, but in only two are the results sufficient to warrant a diagnosis of chronic Nephritis (2.8\%). In 5 cases (8\%) the tests were incompletely done and therefore no deductions were drawn. 
In a certain number of cases $i$ has been said there was an antecedent history of Scarlet Fever or Diphtheria. Renal damage previous to Eclampsia might have beendeduced in these and also in cases where there was a history of pregnancy complicated by $\mathrm{Alb}-$ uminuria before Eclampsia. The following table gives the results of the tests in these patients and also a record of subsequent pregnancies if any occurred.

Dicease previous to Eclampia.

Pregnancy prev. Renal \& Preg. to Eclampia. C.V.Tests. subs. to

Eclampsia.

Scar.Fev.

0

S

B. Scar.F. Diphth.

0

Diphtheria

Scar. Fev.

Scar. Fev.

Diphth.

II

Scar. Fev.

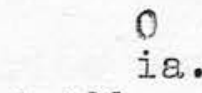

1 Alb.-

Sc.Fev.(twice) 2

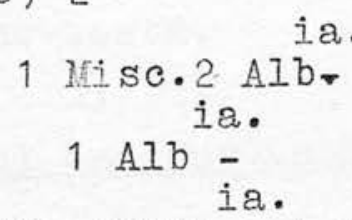

Sc.F.with Nephritis. 2N. 3?Alb.- 1 N.

1 ia.

Sc. F.and

Diphth.
S

S.

S

S

S

S

S

S

S

S

S

S

S

S Now preg.

$1 \mathrm{~N}$.

$1 \mathrm{~N}$.

$1 \mathrm{~N}$.

1 Alb.-

1 "

$-$<smiles>C1CCCC1</smiles>

S $\quad 1 \mathrm{~N}$.
$1 \mathrm{~N}$ and now preg. IT.

ja.

Sc. Fev.(twice) $2 \mathrm{~N}$. 
This table proves that a woman may have a history suggestive of renal impaiment and Eclampsia yet react well to renal efficiency tests. She may also have had Albuminuria of Pregnancy and Eclampsia. and yet react well. She may have had all and yet react well. If one considers the last column as well, one sees she may have both and even have subsequently a normal pregnancy - reacting thus to the most stringent test which can be applied to a kidney.

The next table gives the results of the tests of the 12 patients who failed in one or more tests. It will be seen that some results are perhaps doubtfully abnormal. This is intentional. It is not suggested that all these patients have 'chronic Nephritis in the ordinary meaning of the term - i.e. progressive renal lesions. These patients are those who did not manage to demonstrate that their hearts, kidneys and arteries were completely satisfactory, which was what the 56 abundantly managed to do as judged by these tests.

Record of Renal and Cardio-Vascular Examination. 12 Cases. Age. C.V.Syst. B.P. Urine Blood. U.C.T. Alb. $\quad 1 \mathrm{~m} \cdot \mathrm{HG}$.
A. $30 \quad N \cdot A \cdot D \cdot 132: 74$.
23. $\cdot 95 / 1.9 / 1 \cdot 95$.

B. 38

N.A.D. $100: 62 \quad \mathrm{x}$

C. 45

Impaired.186:110 -

23

$1.6 / 2.1 / 2.1$.

D. 32

$136: 82$

29

$1.6 / 2.0 / 2.95$.

18

$1.2 / 2.0 / 2.15$. 
Age. C.V.Syst. B.P. Urine. Blood. U.C.T. $\mathrm{Alb}$. Irn. HG.

\begin{tabular}{|c|c|c|c|c|c|}
\hline E. 42 . & Impaired. & $128: 70$ & - & 30 & $.9 / 1.7 / 2.1$ \\
\hline F. 29. & $N \cdot A \cdot D \cdot$ & $128: 68$ & - & 30 & $.75 / 1.1 / 1.6$ \\
\hline G. 37 & $\begin{array}{l}\text { Haemic } \\
\text { Ifurmurs. }\end{array}$ & $126: 68$ & $x$ & 23 & $1.35 / 1.4 / 1.95$ \\
\hline H. 44 & Impaired & $140: 72$ & - & 23 & $2 \cdot 5 / 3 \cdot 15 / 3 \cdot 15$ \\
\hline I. 31 & $"$ & $140: 82$ & $-(2)$ & 28 & $1.75 / 2.25 / 2.6$ \\
\hline J. 24 & $\pi$ & $146: 90$ & $x^{1}$ & 36 & $1.15 / 1.15 / 2.15$ \\
\hline K. 40 & $"$ & $140: 96$ & - & 15 & $.9 / 2.2 / 3.15$ \\
\hline I. 38 . & N.A.D. & $110: 70$ & - & 27 & $1.5 / 1.8 / 1.75$ \\
\hline
\end{tabular}

It may be noticed that a defect in heart or arteries is the one most commonly noted. This was a complete surprise to the author when she was drawing up the table. The defects are of varying kinds and consist of slight cardiac hypertrophy, undue arterio-sclerosis (considering patient's age), accentuated second sound in aortic area, undue breathlessness on very slight exertion - evidence of caraiac insufficiency in a small degree. Of these undve arterio-sclerosis is the most common. This observation calls to mind the work of Hinsellmann (Zentral Blatt für Gynäk. 44. 987. Sept 4. 1920.) on the capillary circulation in cases of late Toxaemia of pregnancy. He noted hypertension in capillary segments of the capillary wall with stagnation of the blood as a result of the spasm. On relaxation glow was re-established. Following 
delivery, he noted a return to normal. J.I.Baer and R.A. Reis (Journ. Amer. Hed. Assoc. Feb.1924. P. 526) proved that in normal graviditae the capillary loops are normal and also found that the glow was abnormal in cases of late Toxaemia. They noted that with a general improvement, the local condition improved. Neuermann (Zentralblatt f. Gynak. 44 p.1425. 1920) agrees with these conclusions - changes occurring in the capillary circulation must be felt throughout the entire set of blood vessels and it is possible that permanent traces of the disturbance may be left in the large blood vessels. It is further possible that changes in the small blood vessels show themselves most readily in the renal capillaries. One then recalls the paper of R.D. Mussey (Amer. Journ. Obst. \& Gyn. June 1925 p. 808) which draws a close parallel between eclamptic Toxaemia and acute Glomervlar Nephritis. The Ischaemia which Hinsellmann noted in the capillaries of the finger nail must also occur in the glomerular tuft and it, if it lasts any time, must surely cause secondary changes. The vascular nature of the disease is again stressed by the column of blood pressure readings. These do not correspond very closely with the Urea Concentration Test findings. De Wesselow states (Chem. Observations on Toxaemias of Pregnancy. Journ. of Obst. \& Gyn. Brit. Emp. Vol.29. $1922 \mathrm{p} .21$ ) that in Toxaemias of Pregnancy the Urea Concentration power and the height of the blood pressure show in most cases an inverse relationship. 
Apparently either may return to normal but leave the other abnormal.

It may also be noted that the renal damage, if any, is so slight as to cause no abnormality in the blood Urea Nitrogen. In two cases the Urea Mitrogen is curiously low. I have been unable to find any reason for this.

Of these 12 patients two are believed to have chronic INephritis. These are B. and J. The case of G. is in doubt, She, however, has lately had a subsequent pregnancy complicated by Albuminuria and also post-partum haemorrhage. She is still recovering from this illness; she is an anaemic woman and her general condition is poor, and, in her case, this may account for her unsatisfactory test results. The case of $F$. is specially interesting as she is the patient alluded to before with the strong hereditary tendency to Nephritis. Is it possible that this is a true 'low reserve kidney' showing itself in the abnormal Urea concentration test result? She has no abnormal symptoms.

One case shows abnormal arterial tension $-C$. This patient is one of the 3 who had Eclampsia twice. One may here emphasize the gravity of this recurring Eclampia : One of the cases is dead; one has Hemiplegia, the third has - although she feels well Hypertension.

It has been stated that patients' symptoms often suggest that tests will prove unsatisfactory. 
In the following table statements of how the same 12 patients felt is recorded and in the next column a record of the pregnancy subsequent to Eclampsia.

\section{2 patients with poor Renal Ifficiency Results.}

State of Health.

A. Good.

B. No energy

c. "Headaches.

D. Fairly good.

E. Poor, Lassitude.

F. Easily tired. Headaches.

G. Fair, lassitude.

H. Poor, No energy

I. Good

J. Headache,Poylurea. $1 \mathrm{Alb}$ Always tired.

K. Iittle energy $1 \quad \pi$

1 misc. $v$.

I. Fair.

Thus patients with doubtfully adequate renal tests generally complain of vaguely indifferent health and if they have been pregnant subsequently to the Eclampsia, have probably shown Toxaemia in this pregnancy. This Toxaemia is, so far as we know, the ordinary 'Albuminuria of Pregnancy'; it is quite indistinguishable from the Albuminuria of pregnancy which has occurred in patients whose tests are normal. The medical attendant did not suspect in any case pregnancy complicating chronic Nephritis. 
It will be noted that one patient has had $1 \mathrm{H}$. and 1 a.? N. pregnancy after Eclampsia; that is all tle remaining subsequent pregnancies are complicated by Albuminurea. The normality of the pregnancy marked N. is in no doubt as the patient attended the Antenatal Department of the Royal Haternity Hospital regularly and nothing abnormal was noted during pregnancy, or while she was in Hospital at confinement. Her poor Unalp Tweration which she was included in this list, cannot be accounted for by the present pregnancy, because the test should not vary in pregnancy, although the Blood Urea may then be low, because Urea is of course, a non-threshold substance. The pregnancy marred ?N. is of doubtful normality. This patient never saw a doctor during this pregnancy. It certainly went to term and she remembers nothing wrong.

It is perhaps worth noting that 7 of these 12 patients stated voluntarily that they had 'never got over Eclamnia' - this, of course, before they knew of the results of the tests-but that only two - B.and veria when dischanged from Hospital. J, $J$-who has now chronic Nephritis with Albuminuria, had albumen on discharge after her subsequent confinement, of which the pregnancy was complicated by Albuminuria.

It might conceivably be said that in these 12 cases the permanent damage, if any, had occurred before Eclampsia, and either had been aggravated or had been entirely unaffected by it. A table has the fore been drawn up of the previous illnesses 
and pregnancies of these 12 women.

\section{Prev. IIInesses.}

A.

B. Rheum. F.,Appendicitis.

C.

D.

E. Rheum. F., Gastritis.

F. Scar. F. with Nephritis and other exanthemata.

G. -

H. Measles

I. "

J. -

K. Scar. Fev.

I. " (Twice)
Prev. Pregnancies.

3 N. 1 Hisc.

2 N. 1 ?N.

$7 \mathbb{N}$.

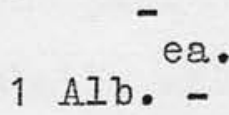

$2 \mathrm{~N}$.

Three of them have had Scarlet Fever but only one abnormal pregnancy occurs. Comparison of the previous and the subsequent pregnancies is most instructive, and proves that some diminution of power for healthy child-bearing has certainly occurred, and the fact that 3 of the 9 cases of Scarlet Fever which occurred in the complete series are found in this list is also suggestive.

It has therefore been shown that if a woman has impaired kidneys her post-eclampic pregnancies will almost certainly be complicated, but that is far from saying that those wose kidneys are satisfactory have had had healthy pregnancies subsequently to Eclampsia. The subsequent pregnancies are now con. 
considered.

\section{SUBSEQUTENT PREGNANCIES.}

Of the 74 women, 32 did not become pregnant again. This leaves 42 women who have had between them 67 subsequent gestations. One woman died as a direct result of a subsequent gestation - $2.38 \%$ mortality - or 1 gestation in 67 proved fatal.

It has already been mentioned that the child of the elamptic mother is frequently still-born. The commonest question which the post-eclamptic patients ask is whether they can safely become pregnant again; the next whether pregnancy will probably end in another still-birth. To answer them the doctor must know the result of many subsequent pregnancies in many cases as well as the circumstances of the individual who is asking.

of the 67 gestations 7 are in progress, 6 have ended in abortion or miscarriage. There have therefore been 54 labours; 48 of these have ended in live births ( $88.89 \%$ ) The 6 still-births could not be accounted for on obstetrical grounds. 4 occurred in cases of Albuminuria, one in a case of (recurrent) Eclampsia and one in a normal pregnancy. TYPE OF SUBSTEUENT GESTATIONS.

This from the point of view of the patient is the most practical point of the enquiry. Hany of the women refrain from again becoming pregnant, although they keenly desire children, because they think, or 
fear, that they cannot healthily bear children.

The following figures give the results of subsequent pregnancies in the 42 women under review.

7 of the natients are pregnant at the time of examination; all are under medical care. 5 of the pregnancies are proceeding normelly. 1 patient has Albuminuria. 60 gestations are thus over. 6 ended in abortion or miscarriage. 36 proceeded normally, 3 ter minated in Eclampsia, and 15 were complicated by Albuminuria. $\quad 3$ of the cases of Albuminuria were severe enough to be classed as cases of "Pre-Eclampsia." In 2 cases labour was induced because of the severity of the condition, and in one it came spontaneously before time. The remaining 12 cases of Albuminuria were mila, that is to say they did not present acute symptoms.

\section{These figures may be represented as percentages :-}

67 subsequent gestations.

$10.45 \%$ in progress.

$53.73 \%$ were normal

$26.87 \%\left\{\begin{array}{c}22.39 \% \text { were complicated by Albuminuria } \\ (4.48 \% " \|\end{array}\right.$

8. $96 \%$ ended in abortion or miscarriage.

Of the 42 women who have been pregnant 40 have been pregnant once again.

12 have been pregnant twice again

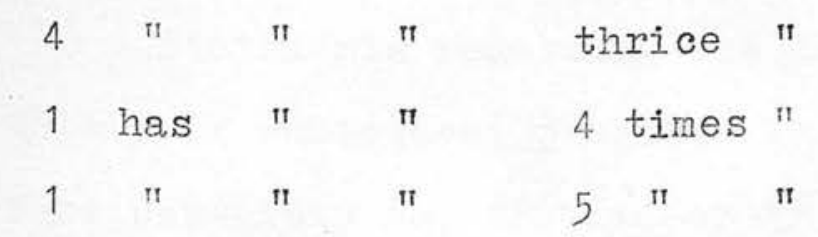


1 has been pregnant 6 times.

1 " " 7 "

\section{of the 40 ' Pirst subsequent pregnancies}

24. proceeded normally to term )

1 was normal and went to term)

$62.5 \%$

11 were complicated by Albuminuria $27.5 \%$

2 " " $"$ Eclampia $5 \%$

2 ended in abortion or miscarriage $\quad 5 \%$

\section{of the 12 "second subsequent" pregnancies}

9 were normal $75 \%$

2. Were complicated by Albuminuria $16.7 \%$

1 ended in miscarriage $8.33 \%$

of the 4 "third subsequent" pregmancies

1 proceeded normally $25 \%$

1 was complicated by Eclampsia $25 \%$

2 ended in abortion or miscarriage $50 \%$.

The fifft-and" fourth subsequent"pregnancy was complicated by Albuminuria.

The 1 "fifth subsequent" pregnancy was normal.

The 1 "sixth subsequent" pregnancy was complicated by Albuminuria.

The 1 "seventh subsequent" pregnancy ended in miscarriage.

\section{Ante-liatal Care in Subsequent Pregnancies.}

Statements regarding the normality or abnormality of subsequent pregnancies can be made with more certainty as, the necessity of antenatal care 
having become very obvious to them, the patients nearly all join a clinique or attend their own doctor. In the present series of 67 gestations all those in progress are being supervised. 44 have been efficiently supervised. The three cases of pre-eclampia all occurred in this series, and one of the cases of Eclampia (recurrent). The remain. ing 23 gestations were either unsupervised or received very inadequate supervision - i.e. the patient paid one visit to a doctor or clinique and did. not seek medical help again until term.

These results argee surprisingly closely with those of J.P. Greenhill (Immediate and Late Results of Eclampsia at the Chicago Iying-In Hospital. Journ. of the Amer. Med. Assoc. July 24. 1926. p. 228.), although his series is much shorter, as only 17 of his 60 survivors of Eclampsia have again become pregnant, and there have only been 18 subsequent gestations. There have been 10 normal gestations ( 9 women). 1 patient was pregnant at the time of writing, 1 patient had Eclampsia again, 3 had Pre-Eclampsia and 3 had chronic Nephritis with pregnancy. 3 patients showed evidence of chronic Nephritis subsequent to Eclampia, 15 appeared completely cured, but $40 \mathrm{f}$ the 15 showed signs of Toxaemia in a subsequent pregnancyi.e. $26.7 \%$. This is almost the same as was found in the present series. 2 of Greenhill's patients have died since they had Eclampsia of chronic Nephritis and 3 now have chronic Nephritis, but 4 of the 5 had 
chronic Nephritis before they had Eclampsia. In the present series no patient had chronic Nephritis before Eclampia, so far as is known, and none have since died of it, but 2 have demonstrably got permanently damaged kidneys. The two series therefore appear to prove that Eclampsia produces in rovghly a quarter of the suriviors derangement of the kidneys, and perhaps other organs which becones apparent when these patients are pregnant, but which is imperceptible and undetectible so long as these patients remain non-gravid. 


\section{ALBUIINURIA of PREGNANCY.}

An enquiry similar to that made of 74 cases of Eclampsia has been made of 81 cases of Albuminuria of Pregnancy. All these patients have been treated for this disease in the Royal laternity Hospital, Edinburgh, during the same period - i.e. between Harch 1921 - March 1926. All were discharged from hospital, and all, except those who have died since discharge, interviewed and examined in precisely the same manner. The Blood Urea and Urea Concentration rests have been also performed. All patients have had the disease at least once sufficiently seriously to warrant admission to hospital, but may have had it more than once possibly in a less severe form. The records of the milder attacks have been obtained either from the cases taken at the AnteNatal Clinique or from information supplied by the patients'doctors. The histories therefore go back in many cases before lrarch 1921.

Albuminuria of Pregnancy is a disease of very varying acuteness and to avoid giving long descriptions of cases the following abbreviations have been adopted and shovld be interpreted in the manner described.

Albuminuria $x x x$ - a case of Albuninuria of Pregnancy showing headache, visual symptoms, a systolic blood pressure of at least $155 \mathrm{fm}$. HG. on at least one 
occasion, in which there is a large amount of albumen in the urine and in which fits may aprear imrinent i.e. "Pre-Eclampsia."

Albuminuria $x x$ - a case of Albuminuria of Pregnancy of less acute type in which the blood pressure is not higher than $155 \mathrm{~lm}$. HG and at least $140 \mathrm{~lm}$.HG. on one occasion, with less albumen in the urine and some oedema.

Albuminuria $x$ - a case of mild Albuminuria of Pres nancy with a systolic blood pressure of not more than $140 \mathrm{~lm}, \mathrm{HG}$. - a case which would not probably be admitted to hospital, in which the albumen in the urine is still less in amount, and in which headache, if present at all, is not more than fairly severe.

This classification is vague and is merely used as a rough guide to the type of case; it deals only with the severity of symptoms and signs and does not deal on their duration. This point is separately noted where it has been possible to ascertaintit, as it is believed that it is fully as important as the acute ness of the symptoms when the ultimate prognosis is under consideration.

Another mode of expression must also be elucidated. Some patients were multiparae when they had their first attack of Albuminuria of pregnancy. The nature of the previous pregnancy is, of course, noted and their number, and the pregnancy complicated by Albuminuria is designated the "first abnormal pregnancy", and the following pregnancy, normal or ab- 
abnormal, is called the "first subsequent pregnancy". In 8 of the cases under review the pregnancy complicated by Albuminuria was preceded by a miscarriage. This cannot be classified as a "previous normal pregnancy", and has therefore been called the "first abnormal pregnancy" to avoid confusion, but in all except these instances the term "first abnormal pregnancy" is synonymous with "first attack of Albuminuria."

AGE. The average age at which the 82 patients first developed Albuminuria of Pregnancy is 29.6 years. The youngest was 16 years old and the eldest was 43 .

PARITY. 58 of the patients developed this disease in their first pregnancy - i.e. Primigravidae 69.5\% The parity of the remainder was as follows :-

$\begin{array}{ccccc}6 & \text { patients were } & 1 & \text { parae. } \\ 4 & " & " & 2 & " \\ 4 & " & " & 3 & " \\ 1 & \text { patient was } & 4 & \pi \\ 3 & \text { patients were } & 5 & " \\ 4 & " & \pi & 6 & " \\ 2 & " & " & 9 & "\end{array}$

PREVIOUS PREGIVANCIES. The 23 multiparae have had between them 81 previous pregnancies. All these were normal gestations; all went to term; all the children were born alive except one whose death was due to prolapse of the cord. 29 of the gestations 
were supervised by the Ante-Hatal Clinique or by the patient's doctor. All patients recovered completely.

\section{PREVIOUS IIINESSES.}

A record has been made of any illness from which these women suffered before their first attack of Albuminuria. This has been done from the same sources in the same way as in the first series of women who had. Eclampsia. The two tables are much alike except that Scarlet Fever is more commonly a precursor of Albuminuria than of Eclamnsia. 17 patients, i.e. $20 \%$ give a history of Scarlet Fever. Only $12 \%$ of the patients with Eclampsia had had Scarlet Fever. More than half the patients had no previous disease at all.

ILLNESSES occurring previous to ALBUIINURIA. - 81Patient s.

\begin{tabular}{|c|c|c|}
\hline No disease & 40 & patients \\
\hline Scarlet Fever & 17 & $\pi$ \\
\hline Diphtheria & 2 & $\pi$ \\
\hline Other exanthemata & 26 & $\pi$ \\
\hline Tuberculosis & 3 & $\pi$ \\
\hline Pleurisy & 3 & $"$ \\
\hline Bronchitis & 1 & $\pi$ \\
\hline Rheumatic Fever & 2 & $\pi$ \\
\hline Chorea & 1 & "I \\
\hline Tonsillitis & 5 & " \\
\hline Influenza & 2 & " \\
\hline Pneumonia & 5 & $\pi$ \\
\hline Appendicitis & 1 & $\pi$ \\
\hline Typhoid & 2 & $\pi$ \\
\hline
\end{tabular}


Anaemia 4 patients.

Dysmenorrhoea 2 "

Syphilis 4

? Renal Disease $3 \pi$

It will be noted that 3 patients give a doubt ful history of antecedent rens disease. Further particulars of their cases are as follows :Mrs. A. had in childhood a mild attack of Acute Nephritis. She developed Albuminuria at the 28 th week or her first pregnancy having been healthy until then. She was treated for 12 weeks for mild Albuminuria of Pregnancy - i.e. until term - when she was delivered of a live child. The Albuminuria did not clear up under treatment, but was never of more than moderate severity. The blood pressure did not rist over $145 \mathrm{Mm} \cdot \mathrm{HG}$. By the $10 \mathrm{th}$ day of the puerperium the blood pressure had fallen to normal, but the Albuminuria persisted for an unknown further period. Her health is good; there is no Albuminuria and her tests are satis factory. She has not again become pregnant.

Mrs. B. when aged 20 had ? acute Nephritis. She recovered completely. Five years later she became pregnant but miscarried at the third month. She again became pregnant and had Albuminuria of $x \times x$ severity from the 32 nd to the 34 th week when labour was induced. Her recovery was slow. On discharge from hospital her blood pressure wais raised and albumen was still 


\section{1.}

present in the urine. This persisted between the 2nd and 3 rd. pregnancies. The Alburninuria remained. mild until the 32nd. week of the 3 rd pregnancy when it became of $\mathrm{xx}$ severity. The pregnancy went to term. The raised blood pressure and Albuminuria remained during the puerperium. Her tests are unsatisfactory and her kidneys are now undoubtedly damaged.

Mrs. C. had'Dropsy'in childhood. Her Pirst three pregnancies were nomal. Her fourth was accompanjed by severe Albuminuria associated with Hydatid Mole. The Albuminuria began at the 16 th week and was of the $\mathrm{xxx}$ severity. Gestation was interrupted at the 19 th week. Headache, which had been severe, and all other symptoms and signs rapidly disappeared. Her health is very good; she has not been pregnant again and her tests give excellent results.

It will be noted that $B$. is the only case in whom renal efficiency tests are poor and in her case also Albuminuria persisted between the second and third pregnancies. This fact alone pointed to renal impairment. In the case of $A$ and B. the Nephritis appears to have damaged the kidneys so that a pregnancy revealed their inadequacy. Both had good health until they were pregnant. In the case of Mrs. C. the early Nephritis appears to have no connection with the Albuminuria of Pregnancy, as there were three normal pregnancies intervening between the two. What, if any, influence the hydati- 
hydatidiform degeneration may have had, it is impossible to say.

In this connection of associated renal disease two other cases must be mentioned. Mrs. D. had no renal disease and only trivial ailments in childhood and adolescence. She had three nomal/pregnancies. When three months pregnant with her fourth child, she had an attack of acute Nephritis. Therapeutic abortion had to be performed and during the puerperium decapsulation of the kidneys. Since then she has been under continuous medical observation for chronic Nephritis of a mixed azotaemic and hydraemic type. During this time she has been twice pregnant, i.e. she has been pregnant six times altogether. She spontaneously miscarried in her 5 th -2nd. abnomal pregnancy at the third month. Her last pregnancy was intermupted artificially at the 35th week. She had persistent 'mild' Albuminuria; blood pressure never rose above $140 \mathrm{Mm} \cdot \mathrm{HG}$. systolic. The child was alive. Her recovery was slow and incomplete and although the Albuminuria was only of a $\mathrm{x}$ severity and never assumed an acute form, her condition was rather worse than before.

Mrs. E. must also be alluded to here, although her only illness has been Scarlet Fever, because she has a hereditary tendency to develop renal disease. Her case should be compared with that of the patient who had Eclampsia and in whose family chronic Nephritis also occurred with great frequency. Mrs. $E^{\prime}$ S attack 
of Scarlet Fever was not severe and was uncomplicated. She has otherwise been very healthy except during her two pregnancies. These have been very carefully super vised by her own doctor until her admission to hospital. In the first pregnancy Albuminuria appeared at the 6 th month. In spite of all treatment the condition progressed and the pregnancy had to be terminated at the 36th week for $\mathrm{xxx}$ degree of Albuminuria. Her recovery was slow, but Albuminuria disappeared in the puerperium. Her second pregnancy was similarly complicated; albuminuria reappeared at the same period of gestation, but her condition did not become so acute. The pregnancy was terminated at the 39 th week for Albumenuria of $x x$ severity. Albuminuria again disappeared. but recovery was slow. Both children are alive and healthy. Her family history so far as it could be obtained is as follows : She is an only child; her father was one of a family of six. All died before the age of 55 of chronic Nephritis. Her paternal grandfather died of Nephritis. She has been told that grand aunts and uncles died of Nephritis, but has been unable to ascertain the truth of the statements. She is now 35 years of age, apparently a very healthy woman. Her renal efficiency tests are all good. She is most anxious for more children, but has been forbidden to attempt another pregnancy by her doctor. This case appears to be one of deficient renal margin detected by pregnancy. Had the history been wanting, it could in no way have been differentiatedfrom the ordinary case of Alburninuria. It is curious to note that the 
first attack was more acute than the second. It was only in the first attack the fits were imminent. This tendency for the first attack to be the more acute has been noted in a large proportion of cases in which no renal damage has been proved to have been present.

A record is now given of those patients who have had Scarlet Fever in adolescence. Scarlatinal Nephritis did not occur, so far as is known, in any of these crses.

Record of 17 patients who had Scarlet Fever and later Albuminuria of Pregnancy.

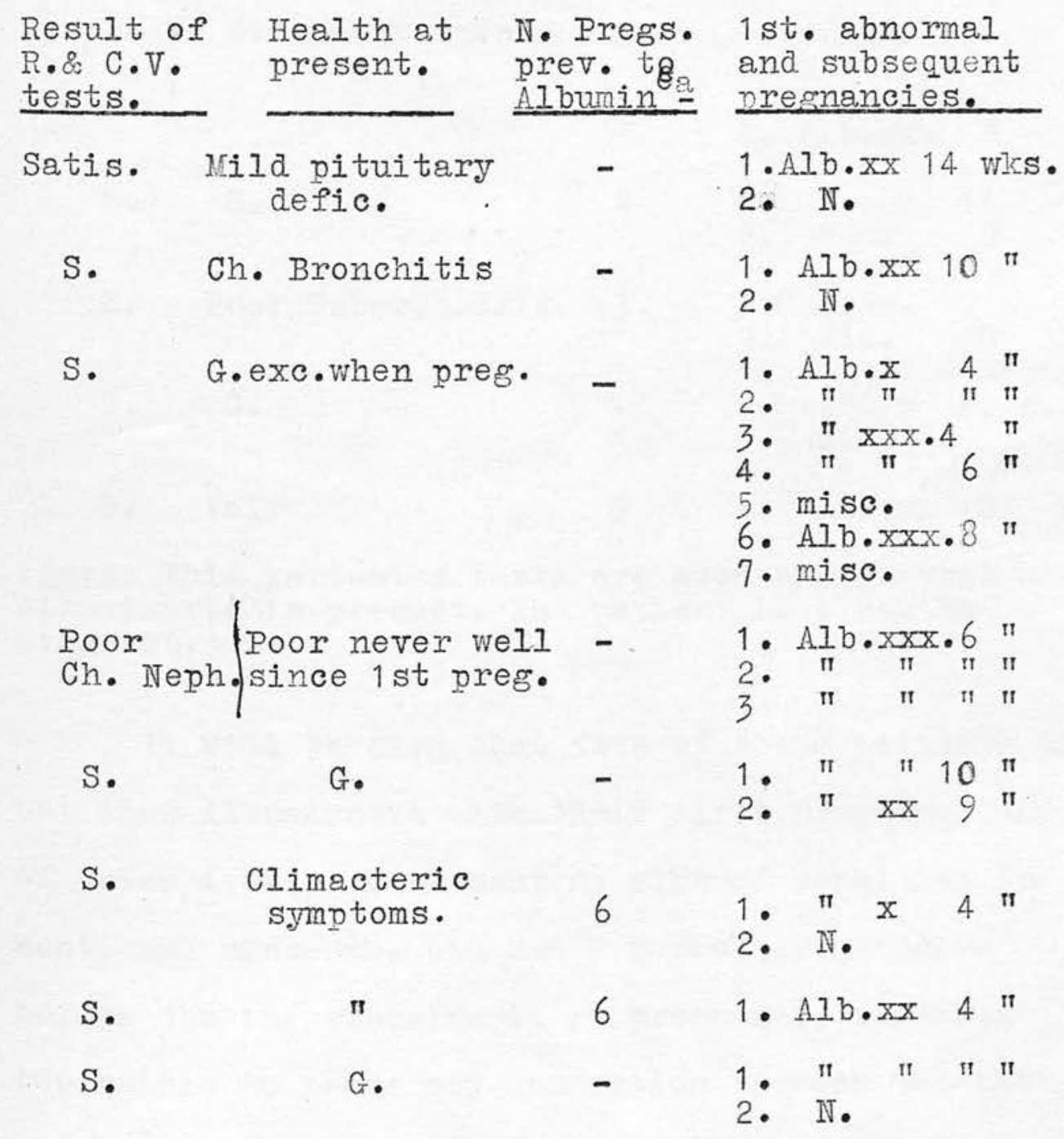




\begin{tabular}{|c|c|c|c|}
\hline $\begin{array}{l}\text { Result of } \\
\text { R.\&.C.V. } \\
\text { Tests. } \\
\end{array}$ & $\begin{array}{l}\text { Health at } \\
\text { present. }\end{array}$ & $\begin{array}{l}\text { N. Pregs. } \\
\text { prev. to } \\
\text { Albuminea } \\
\end{array}$ & $\begin{array}{l}1 \text { st abnormal } \\
\text { and subsequent } \\
\text { pregnancies. }\end{array}$ \\
\hline Poor & $\begin{array}{l}\text { Ch. Neph. } \\
\text { poor. }\end{array}$ & 9 & $\begin{array}{l}\text { 1. ?Alb. } \\
\text { 2. Misc. } \\
\text { 3. Alb.XXx } 14 \text { wks } \\
\text { 4. Misc. plus } \\
\text { Alb. }\end{array}$ \\
\hline S. & Fair & 1 & $\begin{array}{l}\text { 1. } \quad \operatorname{Misc}_{\|} \cdot 2 \cdot \mathrm{N} . \\
\text { 3. } \\
4 \mathrm{Alb} \cdot \operatorname{xxx} 4\end{array}$ \\
\hline
\end{tabular}

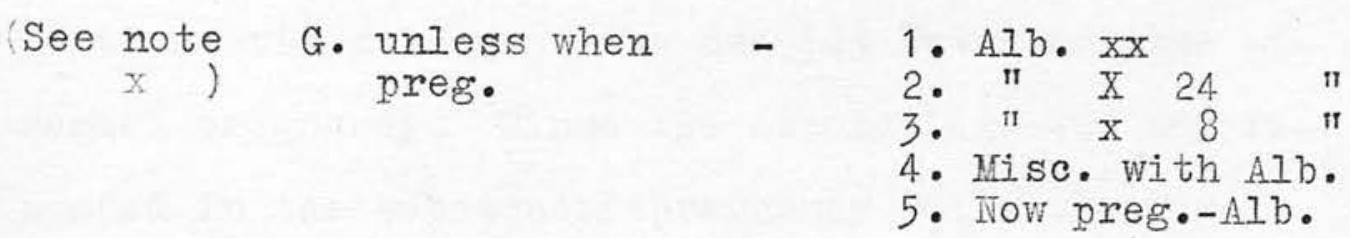

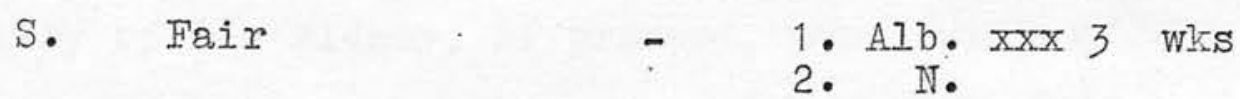

S. G. except when - 1. AIb. 14 " preg. 2. Misc.

3. $\pi$

4. Alb. $x \times x \quad 3 \pi$

S. G. $\quad-1.7 "$ " 11 " 11

$\begin{array}{lll}\text { S. Poor, Tuberculosis. 3. } & \text { 1. Hisc. Alb. } 10 \pi\end{array}$

S. G. $\quad-\quad 3 \cdot \pi \times 2 \cdot \mathbb{N}$.

S. Fair 5 J. A.lb. $\times x \times 10$ wk

(Note. This patient's tests are good except that Albuminuria is present. The patient is 4 months pregnant.)

It will be seen that five of these patients did not show Albuminuria with their Pirst pregnancy and of these 4 show at present no sign of renal impairment, and since the 5 th had 9 normal pregnancies before showing Albuminuria in pregnancy, it seems impossible to trace any connection between the Scarlet Fever and the Albuminuria or the present Nephritis 
Of the 11 patients who first had Albuminuria of pregnancy when primiparae two show kidney damage, and 8 reacted well while the last would probably have reacted satisfactorily had she been pregnant. 7 patients have had at least one normal pregnancy after an abnormal, and one of these has unsatisfactory tests. In these cases also no clear connection exists between the Scarlet Fever and the abnormal pregnancy. Since the abnormality was not repeated in the subsequent pregnency while the disability of the kidney, if present, must remain.

\section{DEATHS.}

of the 81 cases 3 have died since they have had Albuminuria, or almost $50 \%$ ?

1. Of a gastric ulcer. This ulcer was present during the pregnancy and a further complication of it 11. Of ante and post partum haemorrhage at the 5 th month. This patient was a there was no history of renal disease. Her first pregnancy was complicated by severe Albuminuria and ante-partum haemorrhage (not due to Placenta Praevia.) Her 2nd. pregnancy was complicated by severe Albuminuria. It is not known whether the patient had Albuminuria during her third pregnancy as she died almost immediately after admission to hospital from haemorrhage. 111. Of cerebral haemorrhage. This patient died 2 months after delivery. She had three pregnancies all complicated by either $\mathrm{xx}$ or $\mathrm{xxx}$ Albuminuria. It is this not known whether/persisted after her third pregnancy 
or not. Her age was 38 .

Thus in all probability the causes of two of the three deaths were intimately Iinked with the A.lbuminuria.

\section{IIINESSES ASSOCIATED WITh AIBUIINURIA.}

4 patients had diseases associated with Albuminuria. One patient had Chorea Gravidarum; in her next pregnancy Albuminuria recurred without the Chorea. One had Gastric UIcer from which she ultimately died. One had Pleurisy associated with her 2nd attack of Albuminuria. Her next pregnancy was complicated agrin by Albuminuria. One patient had her 1 st attack of Albuminuria ushered in by an attack of Bronchitis. She had had 9 previous normal pregnancies and her three subsequent pregnancies were all abnormal.

The 78 surviving women have all been interviewed, examined in exactly the same way as the survivors from Eclampsia. The same tests and technique have been employed and the following results arrived at.

HEAITH Of SURVIVING PATIENTS. - 78 cases.

33 patients state that they have good health and in all of these no defects were found except oral sepsis and constipation, some degree of which was found in nearly all cases. All these patients gave good results in the Renal efficiency tests done. 7 patients have poor health. One of these 
refused to have any examination made. One has active Tuberculosis; the remainder react unsatisfactorily to the Renal efficiency tests.

4 patients volunteer the information that their health is good 'except when they are pregnant', and that they have a curious and indefinite sensation of tiredness and malaise from the 4 th month or so of gestation onwards. All the patients show good Renal test results and all have had Albuminuria in each of their pregnancies.

Of the 45 patients who have poor or indifferent health 7 react poorly to the Renal efficiency tests. These (45) patients show the following defects on clinical examination.

\begin{tabular}{|c|c|c|}
\hline Anaemia (secondary) & 5 & cases \\
\hline Syphilis (under treatment) & 4 & $\pi$ \\
\hline Heart lesions & 2 & $n$ \\
\hline Pituitary deficiency & 1 & $\pi$ \\
\hline Enlarged Thyroid & 1 & $"$ \\
\hline Toxic Goitre & 1 & $\pi$ \\
\hline Dysmenorrhoea & 3 & $\pi$ \\
\hline Menopausal symptoms & 3 & $\pi$ \\
\hline Cervicitis & 1 & $\pi$ \\
\hline Menorrhagia & 1 & $\pi$ \\
\hline Uterine Fibroids & 1 & " \\
\hline Tuberculosis & 3 & $\pi$ \\
\hline Non specific chronic Iaryngitis & 1 & $\pi$ \\
\hline Neurasthenia & 1 & " \\
\hline Chronic Bronchitis & 1 & $\pi$ \\
\hline
\end{tabular}


Advanced Pyorrhoea

Marked Constipation

Fumanculosis
5 cases.

$3 \pi$

1 in

\section{$\frac{\text { RESULT of INVESTIGATIOI of RWNAT and CARDIO }}{\text { VASCULAR SYSTEIS }}-\frac{78 \text { cases. }}{78}=$}

62 of the patients reacted in a satisfactory manner. 11 patients give a defective result in one or more than one test and 5 patients did not have the whole set of tests performed and are therefore excluded. That is to say -

$81 \%$ or patients give good reactions

$13 \%$ " " " unsatisfactory -poor reactions

$6 \%$ " $"$ were not fully examined.

As in the case of the eclamptic patients it is not claimed that all 13\% have chronic Nephritis, but merely that in at least one respect they did not respond normally. This result should be compared with that obtained in the eclamptic series.

Good result Poor result Tests of R.\& C.V. of R.\& C.V. incompletely tests done.

Eclamptic Series $76 \%$ $16.9 \%$ $8 \%$ Albuminuria " $81 \%$

$13 \%$ $6 \%$.

The following table gives the result of the Cardio-vascular and renal tests in the patients who were considered to react inadequately. 
Age. Parity. C.V.Syst. B.P. Urine BI. U.C.T. Alb. $\mathrm{Mm} \cdot \mathrm{Hg}$.

\begin{tabular}{|c|c|c|c|c|c|c|c|}
\hline A. 33 . & 4. & & $\mathbb{N} \cdot A \cdot D \cdot$ & $140 / 102$ & $\mathrm{x}$ & 28 . & $1.0 / 1.65 / 1.7$ \\
\hline B. 30 & 2 & & Impaired & $142 / 84$ & $\mathrm{x}$ & 30 & $0.9 / 1.1 / 1.6$ \\
\hline C.32. & 6 & & $"$ & $162 / 82$ & $\mathrm{x}$ & $\begin{array}{l}30 \\
N \cdot P \cdot \pi \cdot 53\end{array}$ & $3 \cdot 1 \cdot 2 / 1 \cdot 6 / 1 \cdot 75$ \\
\hline$D .42$ & 6 & & $\mathbb{N} \cdot A \cdot D \cdot$ & $110 / 62$ & - & 24 & $1.7 / 1.75 / 1.85$ \\
\hline 巴. 47 & 13 & & Impaired & $190 / 120$ & - & NPI 46. & $0.9 / 1.7 / 2.1$ \\
\hline$F \cdot 23$ & 4 & & $N \cdot A \cdot D \cdot$ & $124 / 64$ & $\mathrm{x}$ & 25 & $1.7 / 2.4 / 2.4$ \\
\hline$G \cdot 31$ & 3 & & $"$ & $120 / 62$ & - & 21 & $0.9 / 1.7 / 1.85$ \\
\hline $\mathrm{H} .40$ & 7 & $?$ & Impaired. & $142 / 82$ & $\mathrm{x}$ & 23 & $1.9 / 2.5 / 2.8$ \\
\hline I. 39. & 6. & & $"$ & $135 / 86$ & - & 23 & $1.3 / 1.9 / 1.9$ \\
\hline J.33 & 2 & & $"$ & $160 / 104$ & $\mathrm{x}$ & 30 & $2.1 / 1.9 / 1.85$ \\
\hline K.44 & 5 & & N.A.D. & $126 / 82$ & - & 30 & $1.6 / 1.9 / 1.9$ \\
\hline
\end{tabular}

It will be seen from this table that of all the tests used the Urea Concentration Test is the most sensitive to minor degrees of impaiment caused by or causing Albuminuria in pregnancy. It is impaired in all instances except one $-F$. It must be noted of this case that the only sign of abnomality in the tests is the presence of Albumen in the urine. This patient was gravid when the tests were made. In all her former pregnancies (4) she has had Albuminuria of $\mathrm{x}$ degree. Three pregnancies went to term; in one she miscarried. The Albuminuria began in two instances at the 4 th month and in one at the 32 nd week, in the test Albuminuria was present when patient came under observation. In all cases all sign and symptom of abnormality disappeared soon after delivery. In her 
5th (present) nregnancy she already, at the 4 th month, has Albuminuria and if she recovers apparently completely as she has done previously, she would not, had she been tested some months later, have appeared in this list. This patient appears to be an example of Kellogg's 'Recurrent Toxaemia of Pregnancy (Amer. Journ. Obst. \& Gyn. Vol V111.1924 p.313) If she has a faulty kidney balance, this is only obvious when she is pregnant, when the additional work required of the kidney proves too severe a strain upon it. The Toxaemia does not become acute and is not due to Chronic Nephritis complicating pregnancy. After considering all the tests and the ages of the patients, it is believed that $A, B, C, E, H$, and $J$. have chronic Nephritis of a low grade. In the case of E. the process has attacked the vascular more than the renal systemand arterio-sclerosis is very well marked, and there are many symptoms of Hypertension. Failure of the kidneys has just begun.

The following list gives the pregnancies of the patients: -

A.1 A.Alb.xx prem.1ab.30th wh. 2,Alb. $x x x$ pr.lab.ind.30th wk. 3) Alb. \& Therapeutic abortn. 24 th wk.

B.1)Hisc. 2) Alb.xxx 32-34th wk. Iab.ind. 34th wk. 3.) Alb.xx 32 wk. lab. ind. 4.0 wk.

C.1,, 2, 3, 3N. 4. Ther. Abor. Ac.Neph. 4thm D Hisc.Alb. 6) Alb.x throughout preg.

D.1), 2), 3), 4), 5) N. 6)Alb. $\times 18$ - 30wk. Prem.lab. 30 th wk.

E.1) -10) N. 11) misc. 12)AIb. $\operatorname{xxx} 18-36 \mathrm{wk} \cdot 1 \mathrm{ab} \cdot \mathrm{ind} \cdot 36 \mathrm{wk}$ 13) misc. Alb. 
F. 1) $A I b \cdot x$ 2) $A I b \cdot 16=40 w k \cdot$ 3) Alb $x$ 32-40wk.4)misc and AIb. 5) $\overline{\mathbb{N}} \cdot \mathrm{AIb}$.

G. 1) N. 2) Alb.xxx 27-30wk lab.ind. 30wk.

3) $\mathrm{Alb} \cdot \mathrm{xx}$ and HPH. 34-40wk.

H. 1)? Alb. prem.1ab. 30wk 2) Alb. Sp.lab.30wk. 3) ?Alb. $\mathrm{xxx}$ 4) ?N. 5) Alb. $\times x \times$. 6) Albxxx. 28-40wk. Cerb.Haem. 7)Alb. 28-40wk. I. 1,-5) N. 6) Alb. $x \times x \times 14-37$ wk.

J. 1) $A I b \cdot x$ 29-32wk. prem.lab. 32wk. 2)Alb.xxx $16-32 w k$. when lab. ind.

K. 1) -4) N. 5) AIb.xx 26-35wk. prem.lab. 35wk.

It will be seen from this table that once the abnormal pregnancy has taken place, it has only been followed in one instance, arid this a very doubtful one, as the patient was not under observation, by a normal pregnancy. Patients who react even doubtfully adequately to these tests are almost certain to fail under the test of pregnancy. This point is illustrated as well by the 2nd series of cases as the first (the eclamptic series.) Further, the type of failure is not typical. All degrees of Albuminuria are represented and occur in apparently fortuitous sequency, except that in the cases of the declared Nephritis, the Albuminuria has appeared early. Two of these patients give a history of Nephritis, B. and $\mathrm{C}$. of this series, and have in this connection already been alluded to. Two give a history of having had Scartet Fever, and in both cases Albuminuria appeared with the first pregnancy. The following table gives a list of these same patients with what illnesses, if any, they had 
before their first toxaenic pregnancy.

\section{PREVIOUS DISEASES.}

A.

A. Scar. Fer and other exanthemata. A.lb appeared in 1 st pregnancy. ia

B. Syphilis. Renal Dis. ? Alb - appeared in 1 st preg.

C. Measles. Neph. during 1st toxic preg. Alb did not appear in 1 st preg. ia.

D. No illnesses. Alb - did not appear in 1 st. preg.

E. Pneum.,Plevisy and other exanthemata. ia. did not appear in 1 st preg.

F. Scar. Fev, and other exanthemata. Alb appeared in 1st preg.

ia.

G. No illnesses known of. Alb - did not appear in 1 st. preg. ia

H. " "known of. Alb - appeared in 1 st. preg.

I. " " "A.rb - did not appear in ia 1 st preg.

J. Syphilis. Alb- appeared in 1 st preg. ia

K. No illnesses known of. Alb - appeared in 1 st preg.

As was the case in Series 1 therefore, patients who have unsatisfactory tests have in most cases poor health when not gravid and develop toxaemia when pregnant, but as was again seen in Series 1, the fact that the non-gravid, post-toxaemic patient has satisfactory tests does not mean that she will pass normally through a subsequent pregnancy. The report on subsequent pregnancies shows that this is even more obvious in Series 2 than in Series 1. 
TYPE OP"1 St ABNORUAI PREGNANCIES"=

Of the 81 women who were pregnant

15 developed Toxaemia of $x$ severity.

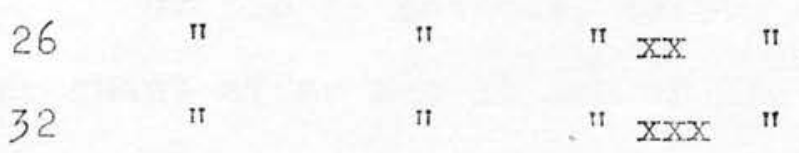

8 gestations ended in miscarriage. There were therefore 73 labours, and, since twin pregnancy occurred thrice, 76 children were born. Of the 73 labours, 57 were spontaneous, 12 were induced and in 3 others induction was started so but labour came on/rapidly that it had already probably spontaneously started. In one case Caesarean Section was performed. Premature labour occurred in $3^{1}$ cases. That is to say, labour came on before term in approximately $.42 .5 \%$ of cases, but this only occurred as a result of treatment in approximately $20 \%$.

\section{RISKS TO IIHE OF FOETUS in allowing"1 st abnormal} pregnancy" to continue.

Of the 76 children 58 were born alive and 18 were still-born. That is to say -

$76.3 \%$ were born alive

$23.7 \%$ "still-born.

One still-birth was the result of a prolapsed cord. No mechanical reason is known to exist to account for any of the other still-births. Some labours occurred so prematurely that the damage of still-birth was much increased but neo-nataldeaths 
are not included in this figure.

RISKS of LIFE to WOTHER in SUBSEQUENT PREGNANCY.

of the 81 mothers, thirty did not become

pregnant after one attack of Albuminuria. Of the

51 who did two have died in a subsequent pregnancy -

i.e. $3.92 \%$

of the 51 women there have been altogether

90 subsequent gestations. Two gestations in 90

proved fatal. $(2.2 \%)$

CHANCE Of IIVING CHIID in SUBSEQUTET GESTATIONS.

Of the 90 subsequent gestations

6 are in progress.

8 have ended in abortion.

6 " " " miscarriage.

There have therefore been 70 subsequent

labours - 61 of these terminated in live births,

9 children were still-born. $(12.9 \%$.) All cases

of still-birth were associated with Albuminuria -

that is to say, no normal subsequent pregnancy terminated in a still-birth.

NUMBER of GESTATIONS in WOMEN who have had ATBUMINURTA Of PREGTANCY.

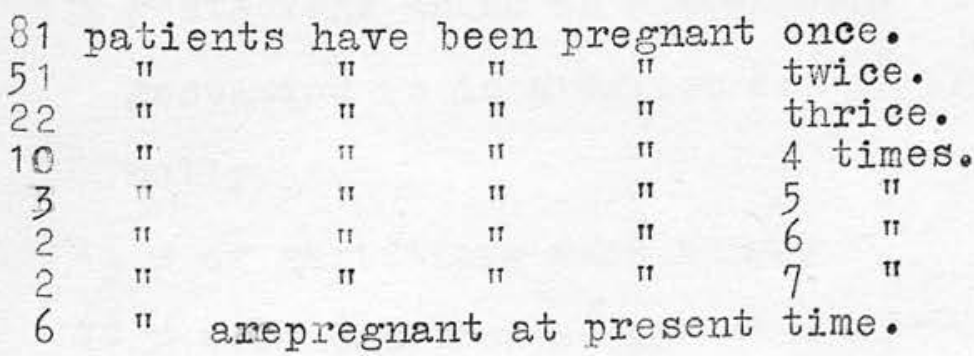

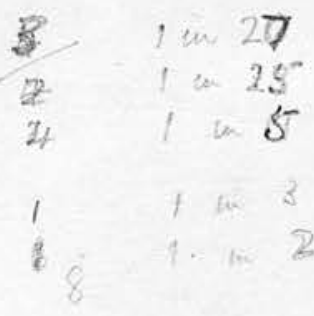


In this table 1 st abnormal and subsequent pregnancies are alone noted, whether normal or abnormal. The previous normal pregnancies of the multiparae, of which there were 81, are not included.

\section{TYPES Of SUBSEQUENT PREGNAITCIES.}

There have been altogether 90 gestations subsequent to one attack of Toxaemia. Of these $44\left(\begin{array}{c}39 \text { were complicated by Albuminuria. } \\ 5 \text { " ? " " }\end{array}\right.$ 26 "normal.

14 ended in abortion or miscarriage.

6 are in progress. Of these 5 are proceeding normally and 1 abnormally.

That is Albuminuria has recurred in $48.89 \%$ of these cases, abortion or miscarriage have occurred in $15.56 \%$, $28.89 \%$ were normal and $6.6 \%$ are in progress.

\section{1 st. SUBSEQUENT PREGHANCIES. - 51 cases.}

of these gestations

21 were normal

11 showed Albuminuria of $x$ severity

$\begin{array}{lllll}4 & " 1 & & & \\ 9 & \pi & & & \end{array}$

5 gestations ended in miscarriage or abortion and 1 gestation is in progress and is proceeding normally.

$4.1 \%$ of gestations were normal

$47 \%$ were complicated by Albuminuria.

There were thus 45 labours which enced in stillbirths in 7 and live births in 38 vases. All still- 
births occurred in association with Albuminuria. The incidence of still births was $15.5 \%$. Induction of premature labour was practised in 5 cases.

\section{"2nd. SUBSEQUENT GESTATIONS"}

22 patients have been pregnant twice after their first attack of Toxaemia.

5 gestations proceeded normally

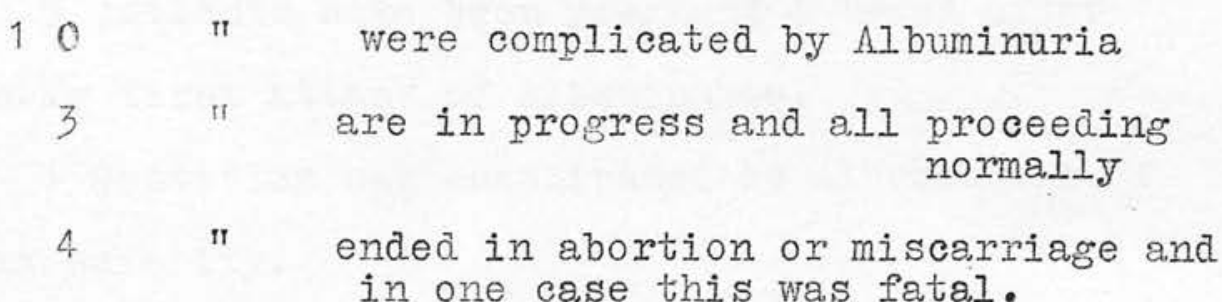

7 Albuminurias were of $\mathrm{xxx}$ severity

" " " $\mathrm{xx}$ "

3 " "

15 labours have therefore been completed. Still birth occurred twice, both times in cases of Albuminuria $(13 \%)$. Four labours were induced prematurely. $22.5 \%$ gestations proceeded normally $45 \%$ "were complicateō by Albuminuria.

\section{3rd. SUBSEQUENT GESTATIONS.}

10. patients have been pregnant 3 times since

their first attack of Toxaemia of Pregnancy. of these

1 gestation proceeded normally

5 gestations werecomplicated by Mbuminuria.

3 ended in abortion or miscarriage and 1 is in normal preogress.

3 Abuminuria were of $\mathrm{x}$ severity

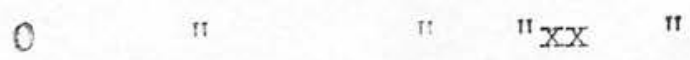

$2 \quad " \quad " x x x "$


In one case a still-birth occurred and one labour wa premature.

$10 \%$ of the gestations proceeded normally.

$50 \%$ " " were complicated by

Albuninuria.

4th. SUBSEQUENT PREGIVANCIES.

3 patients have been pregnant 4 times after their first attack of Albuminuria.

1 Gestation was complicated by Albuminuria of xxx severity

1 ended in Miscarriage.

1 patient is now pregnant and has Albuminuria.

Thus only 1 gestation has terninated in labour. The child was full time and still-born.

\section{5th SUBSEQUENT PREGNANCIES.}

2 patients have had pregnancies 5 times after their first attack of Albuminuria. Both were complicated by Albuninuria of $\mathrm{xxx}$ severity

\section{6th. SUBSEQUENT PREGNANCIES.}

2 patients were pregnant 6 times after their 1st. attack of Albuminuria.

1 Gestation ended in miscarriage.

1 " was complicated by Albuminuria.

The chances that Albuninuria will recur in a subsequent pregnancy thus seen to be very great 
as there is after one attack a very definite predisposition to develop the disease again; but in only a very small number of those who develop the disease, even develop it several times, is it possible to detect any renal or other impairment. More than half of the gestations subsequent to Albuminuria of Pregnancy are abnormal, but the women, as those of series one, appear and remain, for the most part, well so long as they are not pregnant. The figures obtained in the 2nd series may be compared.

ns.

Gest. subs. to 1 attack 1 st.Series. 2nd.Series. of Toxaemia.

Albuminuria

$22.39 \%$

$48.89 \%$

Eclampsia

Norma.I

n ge.

Abor- or Misc -

$4.48 \%$

$53.73 \%$

$28.89 \%$

Abor- or lisisc

$8.96 \%$

$15.56 \%$

Gestations in progress

$10.45 \%$

$6.6 \%$

Chances of a living child in subseguent gestations.

(Calculated per 100 labours.)
1 st, Series
$88.89 \%$
2nd.
$87.1 \%$ 


\section{CONCLUSIONS.}

From the foregoing figures it has been shown that the percentage of recurrence of Toxaemia is much higher after Albuminuria than after Eclampsia, but if the two series are taken together $37.88 \%$ of the subsequent gestations are complicated by some degree of late Toxaemia. As Toxaemia occurs in roughly $2.5 \%$ of all pregnant women, there is a definite predisposition to recurrence, especially when it is remembered that all toxaemic conditions have a much greater incidence in primiparae than multiparae, as $2 / 3-3 / 4$ of the cases occur in primiparae. First pregnancies form 1/4 to $1 / 5$ of all pregnancies and thus the liabjlity to Toxaemia is a bout 10 times as great in primiparae as it is in multiparaep (Fairbairn. Gycaecology \& Obstetrics. Oxford Medical Publications p. 166). In only a small number of cases can the tendency to develop Toxaemia be explained by the presence of Nephritis.

The frequency of recurrence found in this series of cases is similar to that noted by other observers. Gibberd. (Results of Albuminuria occurring during Pregnancy. Proceedings of the Royal Society of Med. VoI. XX1. No. V. p. 832.) found that of 28 women who became pregnant after an attack of Albuminuria 19 (68\%) developed Albuminuria again. Young (Edinb. 
Med. Journ. Apr. 1927. ) found that the recurrence rate of Toxaemia, convulsive or non-convulsive, was 31.8 \% of cases which had Eclampia. Wolfe and Zade (Nonat Sch. für Geburtshüle \& Gynak. Berlin. XI. No. $6 \mathrm{p} .633$ ) found that cases of Nephropathia in pregnant women tended to recur but that dvring pregnancy the different forms of kidney disease cannot be distinguished with certainty.

Bunzl (Statistical Review of Toxaemias of Pregnancy. Amer. Journ. Obst. \& Gyn. June 1924) followed 133 cases of Toxaemia of varying degrees of severity. He found that 55 showed cardio-vascular or renal changes $10-22$ months after their discharge from hospital. 60 of the cases were pregnant when seen or had had another presnancy, and of these 31 showed signs of Toxaemia.

Greenhill (Immed. and Late Results of Eclampsia Journ. Amer. Hed. Assocn. July 24. 1926. p.228) states that chronic Nephritis is rarely found after Eclampsia unless it was present before Eclampsia, and that 26.7 percent of pregnancies (18 cases) occurring after Eclampsia are complicateả by some degree of Toxaemia. J.W.Harris (After Effects of Late Toxaemia of Pregnancy. Bulletin John Hopkins Hospl. Apr. 1924) followed up cases of Eclampsia and Pre-eclampia and concluded that "We are not justified in assuring those who have suffered from Eclampsia or $\mathbb{P}$ re-Eclamp sia that they may face future pregnancies without 
fear of toxic complications." Gestations which occurred in patients who appeared heally one year after pre-eclampsia were all normal. Patients who showed signs of chronic Nephritis one year after preeclampia had pregnancies complicated by Nephritis. He examined 30 cases of chronic Nephritis complicated. by pregnancy one year after their pregnancy. In all cases the disease had advanced.

The outlook of the survivor of Eclampsia is definitely better than that of the woman who has had Albuninuria. On the other hand, a pregnancy after Eclampia must be carefully supervised and even if it occurs in the axparently healthy woman, it may develop Toxaemia. Among the cases grouped as "Albuminuria of Pregnancy" different conditions occur and if these could be differentiated the difference in prognosis would be further stressed. Among them occur :1. Cases with an undoubted renal basis. These are not common but are easily differentiated from others. Chronic Nephritis is present before pregnancy, aggravated by pregnancy and remains after pregnancy. When pregnancy does occur, miscarriage is frequent. Nitrogen retention in the blood, cardio-vascular changes and possibly eye changes can be seen. 2. Cases of Acute Toxaemia. Among the cases of severe Albuminuria there are some which would in the absence of treatment develop Eclampsia. The prognosis as regards future pregnancies of these cases is the 
same as that for cases of Eclampsia. Could these cases be eliminated from the series of Albuminuria of Pregnancy, the percentage of recurrence of Toxaemia would be increased in the remainder. 3. When cases belonging to the two fore-occurring groups have been excluded, a large number of cases of un nown origin remain. They show no Nitrogen retention in the blood, no sign of renal impaiment, when non gravid. They remain healthy women when not pregnant, but when pregnant develop Toxaemia of any degree of severity, though usually Albuminuria begins later in regnancy than it does in the cases belonging to group 1, and often the first sign of approaching toxamia is a rise of blood pressure. In a certain number of these the tendency to develop Toxaemia may be doubtrully correlated with a history of some disease commonly associated with Nephritis or with an attack of Nephritis with apparentiy complete recovery, but in the majority no such history can be obtained. During the toxaemic pregnancy the kidney may be apparently greatly deranged, but its capacity of recovery is apparently very great and all signs of disease disappear in the puerperium. If, however, the test of complete recovery is a subsequent pregnancy, it has not been complete for, under the stress of pregnancy, the kidney will again show signs of dis-

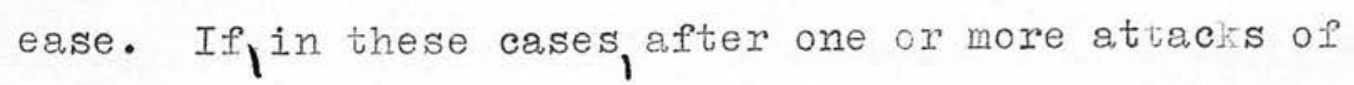
Toxaenia, permanent traces of kidney damage remain in the puerperium, the changes which remain are indis- 
indistinguishable from those which occur in cases of 'mixed' Nephritis except that the lesion may not progress unless in the presence of pregnancy. Often, however, 4 or even more successive toxaemic pregnancies may be experienced, but signs of renal damage disappear in the puerperium; the degree of Toxaemia does not in successive pregnancies become more severe nor its duration more prolonged. Group 3 in our present state of knowledge must be subdivided into -

a) Cases of Recurrent Toxaemia of Uninown origin. b) "1. with a ? renal basis.

By b) is meant cases which have a subliminal Nephritis upon which is grafted "pregnancy kidney". These cases under the added load of pregnancy show renal inefficiency. Some Authorities (e.g. Stander and Peckham Aner. Journ. Obst. \& Gyn. May 1926)Classification of Toxaemias of Later half of Pregnancy) wovld consider the milder cases of this group types of "Low Reserve Kidney".

Until the nature of the extra, work demanded of the kidney by pregnancy, or the nature of the disadvantage under which it labours during pregnancy are known, the types of renal failure under pregnancy cannot be classified. It is known that in pregnancy the blood Urea is low (Chem. Observations on Toxaemias of Pregnancy. de Wesselow Journ. Obst. \& Gyn. Vol. 29. 1922 p.21.) and it has been shown by 
Addis that in normal individuals the blood Urea may be increased. or diminished by changes in the Hitrogen intake. I have no figures of the Nitrogen intake of pregnant women but some Nitrogen must be required, how ever, for new tissue construction. The Non-Protein Nitrogen of the normal pregnant woman seems to be about the same as that of the non-gravid woman. Some of the unknown Nitrogen constituent of the blood must have increased to account for the altered ratio between the Blood Urea and the Non-Protein Nitrogen. Possibly this altered balance places the lkidney at sore disadvantage. At what period of gestation the Nitrogen balance changes from the normal non-gravid ratio to the normal gravid ratio is unknown. Should it occur at or about the 6 th month when symptoms of hyper tension and Albuminuria often first appear, some connection might be surmised. Until some method has been evolved of measuring hepatic efficiency, biochemistry cannot differentiate between the 'Hepatic' and 'Renal' types of Toxaenia. Caldwell and Iyle (Amer. Journ. Obst. \& Gyn. July 1921 p.17) state that the effect of the liver in altering the Nitrogen partition of the blood is still not understood and that attempts to differentiate Hepatic and Renal lesions on this basis is not safe, for to interpret a high undetermined Nitrogen fraction (indicated by a low ratio of Urea Nitrogen to Non Protein Nitrogen) as a failure in deaninisation on the part of the liver is not 
justified. If from repeated tests the blood Urea is found to be rising and the Urea Concentration Test to be falling, irreparable kidney damage is imminent and may have occurred. The sooner these findings are noted in the gestation and the sooner Albuminuria appears, the greater is the likelihood that some degree of Renal failure is the cause of the Toxaemia. The practical outcome of an enquiry such as this is to emphasise the importance of the work of the Ante-Natal and Post-Natal Cliniques. While knowledge of the changes which occur in the normal pregnant and puerperal woman are so scanty, knowledge of the

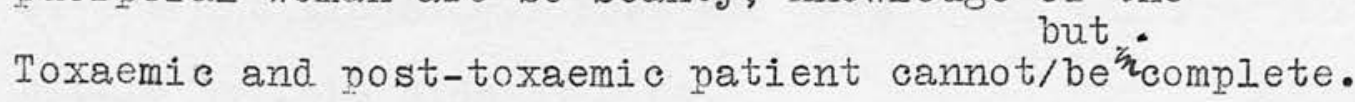
The benefit to the toxaemic patient herself cannot be over-estimated. The incidence of Eclampsia is enormously reduced in the presence of ante-natal care, though fulminating cases $\lambda^{\text {still }}$ occur. lifilder forms of Toxaemia are dealt with and discovered early. A precise knowledge of the time and mode of onset of a Toxaemia is invaluable in assessing the dangers of continuing the pregnancy. It is also invaluable in class. ifying the Toxaemia - a classification which can only be made by the post-natal observer. No accurate ultimate prognosis should be attempted without it, and if future pregnancy occurs, it is also very valuable information.

If the worth of the ante-natal clinique is important, that of the post-natal is no less so in this 
connedion. If the return to normal is incomplete, succeeding pregnancies will certainly not be normal and, should pregnancy occur, the patient's chances of obtaining a live child are much poorer than those of the healthy woman. If the return to normal is slow, it is likely that a subsequent pregnancy will be abnormal. Even if the return to normal is rapid, the possibility that the succeeding pregnancy will be toxaemic is greater than in a woman who has had normal pregnancy or who is a healthy primipara. For the furtherance of knowledge as well as for the benefit of the individual all post and ante-natal information should be laid side by side.

In view of the danger which the toxaemic patient muns, the value of Induction of Iabour must be emphasized ; particularly induction in a patient who is known to have had one toxaemic pregnancy, and after viability of the child has been reached. In this case the child's interests march with the mother's. Noninterference gives little practical gain and may result in great loss. It is impossible not to think that mary cases of Albuminuria are carried on foolishly long. An obstetrician should always seriously consider induction in every case of Albuminuria which has persisted, in the presence of treatment, for over three weeks, even if the case presents no acute features. The following scheme for observation of the toxaemic case in the puerperium is suggested in Hospital cases. 
1. Patients should be kept in hospital for three weeks post partum at least. Regular urinary analysis and blood pressure readings shovld be made. Before discharge the eye grounds should be examined and a Urea Concentration test done. If any of these results are abnormal, blood analysis should be made. The patient's gentral condition should be noted and a tentative diagnosis of the type of toxaemia made. 2. Three months post partum the patient should report at the post-natal clinique. Her general condition and her symptoms, if any, should be noted. A urinary analysis and a blood pressure reading should be taken, and, in the presence of abnormality, a blood analysis and an ophthalmoscope examination. The diagnosis should be reviewed and corrected if necessary.

3. If the patient has apparently recovered completely at the time of the second examination, she should report again one year after delivery. If she shows any abnormality she should report 6 and 12 months after delivery, and each time the same examination should be made. Changes which persist for a year may be regarded as permanent and the patient classified accordingly.

4. In the event of a subsequent pregnancy occurring, all post-natal data with the diagnosis of the type of Toxaemia should be placed in the hands of the attending Obstetrician.

5. All patients who have had late Toxaenia of 
Pregnancy of any degree should be instructed to report to the ante-natal clinique if they know or suspect that they are pregnant.

Iong continued observation of the post-toxaemic patient is necessary for an accurate classification of the Toxaemia, for an accurate vitimate prognosis in the individual and for an effective guide to treatment in the presence of enture pregnancies.

\section{SUISARY.}

1. About a quarter of the pregnancies which occur subsequent to Eclampsia are complicated by some degree of Toxaemia.

2. Almost half of the pregnancies which occur'subsequent to Albuminuria are complicated by some degree of Toxaemia.

3. The earlier Albuminuria begins in pregnancy and the longer it persists, the likelier is it to cause renal damage and the likelier is it to recur in a future pregnancy.

4. Recurrence of Toxaemia occurs in the absence of any detectable trace of renal impairment.

5. If traces of renal damage are absent, and if patients do not become pregnant, they remain in good health. 
1. Stroganoff - Journ. of Obst.\& Gyn. Brit.Emp. $1923 \mathrm{xxxp} \cdot 1$.

2. Williams - Obstetries 5th Ed. p. 622.

3. Eden \& Holland. Hanual of Midwifery 5 th Ed. p. 96 et sequ.

4. J.S. Lawrence - Amer. Journ. Obst. \& Gyn. March 1925.

5. Greenhill - Journ. Amer. Hed. Assoc. July 24 th. 1926 p. 228 .

6. T. Watts Eden. Eclampsia. Journ. of Obst. \& Gyn. Brit. Emp. 1922 p 386

7. J.E. Lawrence - Amer. Journ. Obst. \& Gyn. March 1925 .

8. J. E. Talbot - Toxaemias of Pregnancy - Chronic Sepsis as an Etiological Factor. Aner. Journ. of Obst. \& Gyn. Dec. 1923.

9. Hinsellmann - Zentral Blatt für Gynäk. 44. 987 Sept. 41920.

10. J. I. Baer and R.A. Reis - Journ. Amex. Med. Assoc. Feb. 1924. p. 526.

11. Neuermann - Zentralbl. f. Gynäk. 44 p. 1425.1920.

12. R.D. Mussey - Amer. Journ. Obst. \& Gyn. June 1925. p. 808 .

13. De Wesselow - Chem. Observations on Toxaemias of Pregnancy. Journ. of Obst. \& Gyn. Brit. Emp. Vol. 39. 1922 p. 21.

14. J.P. Greenhill - Immediate and Late Results of Eclampsia at the Chicago Iying-In Hosp. Journ. Amer. Hed. Assoc. July 24. 1926 p. 228.

15. Kellogg - Recurrent Toxamia of Pregnancy. Amer. Journ. Obst. \& Gyn. Vol. V111 1924 p. 313.

16. Fairbairn - Gynaecology and Obstetries Oxford med. Publications p. 166.

17. Gibberd - Results of Albuminuria occurring during Pregnancy. Proceedings of the Roy. Socy. Hed. Vol. XX1. No. V. p. 832. 
16. Young - Edin. Ked. Journ. 1927. Apl.

15\%. Wolfe and Zade - Monats. Chr. für Gebürtshülfe 8. Gynak. Berlin $\mathrm{x}_{\mathrm{T}} \cdot \mathrm{No} \cdot 6 \cdot \mathrm{p} \cdot 633$.

26; Bunzl - Statistical Review of Toxaemias of Pregnancy. Amer. Journ. Obst. \& Gyn. June 1924 .

21: Greenhill - Immed. and Iate results of Eclampsia. Journ. Amer. Med. Assoc. July 24. 1926 p. 228.

22. J.W. Harris - After Effects of Late Toxaemia of Pregnancy. Bulletin John Hopkin's Hosp. Anl. 1924 .

23. Stander and Peckham. Amer. Journ. Obst. \& Gyn. Ira.y 1926.

24. De Wasselow - Journ. Obst. \& Gyn. Vol 29. 1922 p. 21 .

23. Caldwell and Iyle. Amer. Journ. Obst. \& Gyn. JuIJ 1921.0.17.

20. Records of Royal Haternity \& Simpson Memorial Hospltal, Edinburgh. 